\title{
ORGANIZATIONAL STRUCTURE AND TECHNOLOGICAL INVESTMENT*
}

\author{
INÉS MACHO-STADLER ${ }^{\dagger}$ \\ Noriaki Matsushima \\ Ryusuke SHINOHARA ${ }^{\S}$
}

\begin{abstract}
We analyze firms' decisions on their vertical organization, taking into account the characteristics of both the final good competition and the R\&D process. We consider two vertical chains where upstream sectors invest in R\&D. Such investment determines the production costs of the downstream sector and has spillovers on the production and the investment costs of the rival. In a general setting, we show that the equilibrium organizational structure depends on whether the situation considered belongs to one of four possible cases. We study how final good market competition, $R \& D$ spillover, and $R \& D$ incentives interact to determine the equilibrium vertical structure.
\end{abstract}

\section{INTRODUCTION}

IN THIS PAPER, WE ANALYZE HOW FINAL GOOD COMPETITION and the characteristics of the firms' R\&D investment affect firms' decisions about their vertical structure under a general demand system. We investigate this question by proposing a downstream duopoly in which each of the downstream firms has an exclusive

\footnotetext{
*We have benefited from many constructive comments from the Editor, and anonymous referees. We also thank Shingo Ishiguro, Akifumi Ishihara, Atsushi Kajii, David Pérez-Castrillo, Yusuke Zennyo, and seminar participants at the Japan Association for Applied Economics (Nanzan University), Japanese Economic Association (Rissho University), Kagoshima University, and Waseda University for their valuable discussions and comments. We gratefully acknowledge the financial support from the Japan Society for the Promotion of Science (JSPS), KAKENHI Grant Numbers JP15H03349, JP15H05728, JP17H00984, JP18H00847, JP18K01519, JP18K01593, JP19H01483, and JP20H05631, the Generalitat de Catalunya grant 2017SGR-711, the Severo Ochoa Programme grant number CEX2019-915-S, the MCIU and FEDER PGC2018-094348B-I00, Osaka University for its International Joint Research Promotion Program, and the program of the Joint Usage/Research Center for Behavioral Economics at the ISER, Osaka University. The second author is grateful for warm hospitality at MOVE, Universitat Autònoma de Barcelona where part of this paper was written and a financial support from the 'Strategic Young Researcher Overseas Visits Program for Accelerating Brain Circulation' by JSPS. Although Matsushima serves as a member of the Competition Policy Research Center (CPRC) at the Japan Fair Trade Commission (JFTC) our paper does not reflect the view of JFTC. The usual disclaimer applies.

†Authors' affiliations: Department of Economics, Faculty of Economics and Business Economics, Universitat Autònoma de Barcelona, Bellaterra, Barcelona, Spain.

e-mail:ines.macho@uab.cat

ॠInstitute of Social and Economic Research, Osaka University, Ibaraki, Osaka, Japan. e-mail: nmatsush@iser.osaka-u.ac.jp

${ }^{\S}$ Department of Economics, Hosei University, Machida, Tokyo, Japan.

e-mail:ryusukes@hosei.ac.jp
}

(C) 2022 The Authors. The Journal of Industrial Economics published by Editorial Board of Journal of Industrial Economics and John Wiley \& Sons Ltd.

This is an open access article under the terms of the Creative Commons Attribution-NonCommercial-NoDerivs License, which permits use and distribution in any medium, provided the original work is properly cited, the use is non-commercial and no modifications or adaptations are made. 
relationship with an independent supplier that engages in a process innovation. This innovation process may induce $R \& D$ spillovers on the rival's production and $R \& D$ costs. We provide a complete formulation of the reasons for adopting either an integrated or a decentralized structure. We consider how upstream suppliers invest in $R \& D$ depending on the vertical structure, the $R \& D$ spillovers on the rival, and how the R\&D efforts interact with market competition.

Our formulation helps us understand firms' decisions and may explain, for example, why the market structures of the automotive industries in the U.S. and Japan take different vertical organizational forms. The automotive industry depends heavily on external suppliers for car interiors (such as overhead lighting and door paneling) and other components. Those manufacturers engage in many types of $\mathrm{R} \& \mathrm{D}$ (including design and materials), which cause technological spillovers between them (Sako [1996], Aoki and Lennerfors [2013]). While this is common to the industry, different manufacturers choose different vertical structures. Japanese automobile manufacturers often separate the development and manufacturing of critical elements to independently managed entities, which still have close relations with those manufacturers (Ahmadjian and Lincoln [2001]). The degree of vertical integration in those manufacturers is smaller than that in their U.S. counterparts (Cusumano and Takeishi [1991]). Several explanations for the different degrees of vertical integration in the U.S. and Japan have been proposed (Dyer [1996]). Among these, arguments are based on various preferences over the vertical structure, such as the independence of outside suppliers (Scherer [1980], Perry [1989]), or the fear of losing managerial control (Emerson [1962], Pfeffer and Salancik [1978]). Another important aspect is the business culture: trust in suppliers is essential in Japanese cultural norms (Sako [1991], Hill [1995]). We shall show how market interaction, the R\&D spillovers, and the idiosyncratic relationship between the upstream and downstream sectors may also help explain the choice of organizational structure.

We consider two competing vertical chains, each consisting of one upstream and one downstream sector. Each of the upstream sectors decides on R\&D investment, which determines the production costs of the downstream sector in converting inputs into final goods.

The first important element of our model is allowing the existence of crossfirm $R \& D$ spillovers: first, a firm's $R \& D$ investment cost may depend on its rival's R\&D effort; second, the rival's research effort can also affect a firm's production cost. We will refer to the first type of $\mathrm{R} \& \mathrm{D}$ spillovers as spillovers on investment, and to the second type as spillovers on production (Section III provides definitions of both). Each type of spillover may be positive or negative.

The second important element of our model is that the $R \& D$ decision depends on the organizational structure. Under vertical integration, there is no coordination cost between the upstream and the downstream sectors. ${ }^{1}$ They

\footnotetext{
${ }^{1}$ This is consistent with Gibbons [2005, p. 203]: 'the implicit definition of integration in the industrial organization literature is the unification of control rights.' 
share objectives and provide all relevant information and try to help each other to produce the optimal level of $\mathrm{R} \& \mathrm{D}$ for the vertical structure. ${ }^{2}$ Nonintegrated structures suffer from some lack of coordination. We model this problem by assuming that in the case of adopting a separated structure, the downstream and the upstream sectors sign a secret contract with nonlinear tariffs that depends on the downstream bargaining power (which we can interpret as imperfect coordination). Less than full bargaining power leads to an underinvestment in R\&D activities. In other words, as argued by Armour and Teece [1980], more vertically integrated firms make R\&D decisions in more efficient ways.

We show that the equilibrium vertical structure depends on whether the situation belongs to one of four possible cases, which are defined by the two following criteria: (i) whether a firm's R\&D effort helps or harms the rival (nature of the spillovers); and (ii) whether firms' R\&D efforts are strategic substitutes or strategic complements. Case 1 is the situation where a firm's $R \& D$ investment helps its rival, and $R \& D$ efforts are strategic substitutes. Case 2 is the situation where a firm's investment helps its rival, and investment levels are strategic complements. Case 3 is the situation where a firm's investment harms its rival, and investment levels are strategic substitutes. Finally, Case 4 is the situation in which a firm's investment harms its rival, and $\mathrm{R} \& \mathrm{D}$ investment levels are strategic complements.

The analyses of Cases 2 and 3 are easy. Recall that under a separated structure, the R\&D level is lower than in a centralized one. In both cases, the best organization is an integrated structure. In Case 2, aggressiveness for investment by both firms mutually fosters R\&D efforts, which is beneficial for the firms. Hence, each firm adopts a vertically integrated structure as a commitment to engage in more investment to induce its rival to also invest more. In the same way, in Case 3, adopting a vertically integrated structure leads a firm to undertake more R\&D investment, which induces its rival to invest less. That is, firms vertically integrate because aggressiveness in $R \& D$ investment is essential to maintain a strong competitive position in the downstream market.

In contrast, in Cases 1 and 4, firms would prefer to commit to lower $\mathrm{R} \& \mathrm{D}$ efforts. To understand the results on the equilibrium vertical structure, we also need to know whether the decrease in a vertically separated firm's R\&D effort is small or large. Firms may be interested in adopting a decentralized structure as long as the decrease in the R\&D effort (which

\footnotetext{
${ }^{2}$ The innovation process depends on the ability to monitor the latest market and technological developments and to integrate various sophisticated technologies. In the car industry, this can include know-how, commercially sensitive information, cooperation to develop new materials, safety-related innovations, or more complex products or components. The coordination in objectives can also be related to trust or better monitoring, and the difference of this coordination between internal or external R\&D may be substantial. These concerns also exist in the pharmaceutical and biotechnology industries, the service sector, and all industries with material suppliers such as beverage and food sellers or toy producers.
} 
is a function of the bargaining power of the two sectors in a separated structure) is not too strong. For example, in Case 1, with positive R\&D spillovers and substitutability of R\&D efforts, each firm has an incentive to vertically separate in order to induce its rival to engage in more $R \& D$ (as long as the decrease in its own R\&D is small enough). In this scenario, vertical separation allows firms to increase their free-riding on their rival's investment.

To further clarify the forces at work in Case 1, recall that positive spillovers and strategic substitutability of R\&D efforts make firms willing to commit to marginally lower R\&D effort, with the objective of increasing the rival's $R \& D$ effort. Consider the extreme case where in the separated structure, the upstream sector's bargaining power is very high so that it chooses an R\&D effort close to the one implemented by a centralized upstream sector. Then, the cost of vertical separation in terms of the reduction of own R\&D is of a negligible second order. However, this marginal decrease in the firm's R\&D effort induces a strategic effect on the rival's decision that is of the first order. Therefore, if the bargaining power of the upstream sector in the case of decentralization is high, then decentralization is profitable. In contrast, if the bargaining power of the upstream sector in a separated structure is weak, then the R\&D effort falls considerably, and the effect of the fall on profits (direct effect) is no longer marginal. Hence, vertical separation is no longer a good choice. The analysis of Case 4 is similar. With negative spillovers and strategic complementarity of the R\&D efforts, a firm would like to commit to marginally decrease its $R \& D$ effort to lead the rival to also decrease its R\&D effort. Whether or not the firm decides to separate vertically depends on whether, under this organizational structure, the decrease in its R\&D effort is not too large.

Using the example of the Japanese and U.S. car industries, we explain the consistency of our conclusions with the vertical organizations in these countries. We now presume that this industry belongs to Case 1 (or 4), where firms would prefer to commit to decreasing their R\&D efforts to induce the rival to invest more (or less). Japanese suppliers have more bargaining power over automobile assemblers than their U.S. counterparts (Section 5.1 in Matsushima and Mizuno [2013]). Moreover, the degree of vertical integration in those manufacturers is smaller than that in their U.S. counterparts (Cusumano and Takeishi [1991]). Under these terms, our paper provides a plausible explanation for the difference between the Japanese and U.S. automobile assemblers' organizational structures. Japanese firms, whose R\&D investment will decrease little under decentralization, are more likely to adopt vertical separation. In contrast, U.S. firms, whose R\&D effort will decrease more under vertical separation, will be more likely to adopt vertical integration.

Finally, to further highlight the importance of our model settings, we note that in the model studied in the seminal paper by d'Aspremont and Jacquemin [1988], only Cases 2 and 3 emerge. As we have explained, both situations lead to vertical integration. Given this result, one may conclude 
that technological spillovers do not affect the vertical structure decision. However, this conclusion is not appropriate in more general settings (i.e., those that can generate Cases 1 and 4).

The remainder of the paper is structured as follows. Section II summarizes the related literature. Section III describes the model. In Section IV, we consider the incentives for R\&D integrated and separated vertical structures. Then, we classify the possible market structures into four cases that depend on the iso-profit curves and the reaction functions of the firms in the R\&D investment stage. Section $\mathrm{V}$ provides some parametric examples to explain how the incentives to conduct R\&D influence the equilibrium vertical structures. Section VI concludes.

\section{LITERATURE REVIEW}

Our paper considers market structure, R\&D activities, and firms' vertical organization, and is related to three lines of research (see Table I for a summary).

Many papers have provided motives for vertical integration or disintegration by considering the features of the final good market in which firms interact (Bonanno and Vickers [1988], Ziss [1995], Gal-Or [1999], Choi and Yi [2000], Chen [2001, 2005], Lin [2006], Matsushima [2009]). However, those papers do not consider R\&D activities (including process and product innovations), which are indispensable for firms in obtaining competitive advantages over their rivals. They ignore that these activities may be vital in the upstream or downstream sectors. In the case of the car industry, for instance, upstream firms may have a leading role in the innovation process, and knowledge spillovers related to those activities are often inevitable. Then, when the upstream section is critical in the innovation process, whether there is vertical integration or not may have significant consequences.

Another relevant line of literature has studied several effects of vertical structures on the R\&D process. Bolton and Whinston [1993] is the pioneering study of the effect of vertical integration on downstream investments.

TABLE I

RELATED Literature

\begin{tabular}{ll}
\hline Question & Papers \\
\hline Market structure & $\begin{array}{c}\text { Bonanno and Vickers [1988], Ziss [1995], Gal-Or [1999], Choi and Yi } \\
\text { [2000], Chen [2001, 2005], Lin [2006], Matsushima [2009], and so on. }\end{array}$ \\
$\Rightarrow$ Vertical integration & \\
Vertical integration & $\begin{array}{c}\text { Bolton and Whinston [1993], Buehler and Schmutzler [2008], Chen and } \\
\text { Sappington [2010], Liu [2016]. }\end{array}$ \\
$\Rightarrow$ R\&D incentives & Gupta and Loulou [1998], Gupta [2008], Lin et al. [2014], Wang et al. \\
$\begin{array}{l}\text { Market structure and } \\
\text { R\&D technology }\end{array}$ & [2017], Our paper. \\
$\Rightarrow$ Vertical integration & \\
\hline
\end{tabular}


Buehler and Schmutzler [2008] investigate the impact of vertical integration on investment incentives when only downstream firms make cost-reducing investments. ${ }^{3}$ Chen and Sappington [2010] show that vertical integration enhances upstream research efforts under downstream Cournot competition but may decrease those research efforts under Bertrand competition. Liu [2016] studies the impact of vertical integration on investment incentives when both upstream and downstream firms make innovative investments.

In our paper, we are interested in the effects of the market competition conditions and the R\&D investment characteristics on the firms' organization decision. To our knowledge, the closest paper is Gupta [2008], which extends an earlier article (Gupta and Loulou [1998]) in which the manufacturers engage in process innovation without $R \& D$ spillovers in a market formed by two exclusive competing vertical chains. ${ }^{4}$ Gupta [2008] adds R\&D spillovers on the unit cost of production (spillovers on production) in a model with linear demand, linear marginal costs, and linear tariff contracts between the two chains in the case of vertical separation. He shows that vertical integration by both chains is always an equilibrium outcome. In addition, he shows that vertical separation by both chains is also an equilibrium outcome, if and only if the substitutability of their products is sufficiently high. Moreover, vertical separation by both chains induces high investment levels if the spillovers on production are large enough. In our paper, in addition to general $\mathrm{R} \& \mathrm{D}$ spillovers on production, we also consider spillovers on the rival's R\&D process. Furthermore, we investigate a general setting that allows us to focus on the strategic properties of the R\&D investment efforts (strategic substitutes and complements) under a general demand system. Finally, and in contrast to Gupta [2008], we consider secret contracts with nonlinear tariffs or lump-sum transfers in the case of vertical separation. Our results lead to more general and quite different conclusions regarding the firms' decisions on vertical integration or separation. They also show the crucial difference between considering linear contracts between the upstream and downstream sectors (as the previous papers do) and assume secret contracts with nonlinear tariffs or lump-sum transfers (as we do). In our model, vertical separation does not have a strategic effect on profits through the double marginalization problem, which is a critical factor in the previous papers.

Finally, our paper contributes to the connection between organizational economics and industrial organization (e.g., Legros and Newman [2013, 2014]; for a review of vertical integration and market structure, see Bresnahan

\footnotetext{
${ }^{3}$ Milliou and Petrakis [2012, 2019] consider the effect of vertical integration by an upstream monopolist and a downstream firm in a downstream duopoly market with technology spillovers.

${ }^{4}$ There are a few papers that are less related to the consequences of market competition and R\&D investment on vertical organization. Wang et al. [2017] introduce price and quality sensitivities into the Gupta and Loulou [1998] model by using a linear demand system and considering the degree of consumer loyalty. Lin et al. [2014] study a downstream duopoly circular-city model with a three-tier exclusive supply chain. However, technological spillovers of any type are beyond the scope of those papers.
} 
and Levin [2013]). In the organizational economics literature, both transaction costs (Williamson [1975], Klein et al. [1978]) and property rights theories (Grossman and Hart [1986], Hart and Moore [1990]) assume that contracts are incomplete. Those theories discuss whether the market or the organization facilitates the control and coordination of decisions, and provides better incentives for relationship-specific investments. We assume that a vertically integrated organization internalizes the benefit from investments within a unified entry, achieving higher R\&D efforts. We also assume that in a separated structure, the separated upstream investment sector determines its R\&D effort by solely considering its profit through bargaining over the downstream production profits. Hence, the separated upstream sector does not fully internalize the total profits of the vertical chain. ${ }^{5}$ As explained in the Introduction, vertical separation in our model may entail a strategic advantage in $R \& D$ competition. Thus, the cost of integration in our model is the loss of this advantage. This differs from the cost of integration explained in the studies of organizational economics, thereby contributing to the literature on the connection between organizational economics and industrial organization.

\section{BASIC MODEL}

Consider a situation in which two firms or vertical chains, 1 and 2, produce a final good and invest in R\&D before the final good market competition. Each firm consists of two sectors: an upstream sector and a downstream sector. The vertical chains (downstream sectors) compete in the final good market, and they (upstream sector) invest in R\&D.

We denote the firms' R\&D efforts by $e_{i}(i=1,2)$ and we assume that they are publicly observable. When firm $i$ integrates the two sectors vertically, it organizes them as a single entity, which takes into account the joint profits of the sectors. This implies that the R\&D effort is decided to maximize the total profits of the vertical chain. In contrast, if a firm separates the two sectors vertically, each of them has its own objective, and they negotiate the trading terms between them. In particular, in a vertically separated firm, the two sectors in firm $i(i=1,2)$ negotiate a lump-sum transfer $F_{i}$ from the downstream to the upstream sector. ${ }^{6}$ If the negotiation breaks down, the downstream sec-

\footnotetext{
${ }^{5}$ Our view that decentralization reduces R\&D efforts is consistent with Hart [1995, p. 33]: 'In summary, the benefit of integration is that the acquiring firm's incentive to make relationshipspecific investments increases since, given that it has more residual control right, it will receive a greater fraction of the ex post surplus created by such investments.'

${ }^{6} \mathrm{We}$ assume that the payment between the two sectors is a fixed amount; that is, there is no royalty as a function of the production of the final good. This payment scheme is optimal when the contract terms are private information within the two sectors of the vertical chain (so-called secret contracts) and the upstream sector is not involved in the production of the final output after transferring the R\&D outcome. A related discussion is available in Section 3.2 of Caillaud and Rey [1995] (see also Hart and Tirole [1990] and Rey and Tirole [2007] for discussions of secret contracts). In addition, Rockett [1990] explains situations in which licensors of new technology face difficulties in collecting per production fees from licensees.
} 
tor procures the final goods from other competitive upstream firms without any technological advantage. In the third stage, the downstream sectors compete in the final good market using their available technological improvements. We assume that the two chains choose their R\&D effort noncooperatively.

The R\&D investment made by the upstream sector of a firm has a positive effect on the productivity of its downstream sector (e.g., it allows a reduction in production costs), and it may also affect the rival. We consider that a firm's $R \& D$ efforts may affect the rival at two levels: they may influence the R\&D process of the other firm, and they can directly affect the production process of the rival. We shall refer to the first type of spillovers (R\&D spillovers on the rival's R\&D process) as spillovers on investment because they affect the cost of investing in R\&D. We shall refer to the second type of spillovers ( $R \& D$ spillovers on the rival's production process) as spillovers on production because the $R \& D$ generated by the firm directly affects the rival's production process by influencing its production cost.

We formalize the spillovers on investment by assuming that if firm $i$ chooses effort $e_{i}$ and firm $j(\neq i)$ chooses $e_{j}$, then firm $i$ 's R\&D investment cost is $I^{i}\left(e_{i}, e_{j}\right)$, which allows for the rival's R\&D effort to affect firm i's cost of R\&D. Spillovers on investment can be negative or positive. When firms invest in $\mathrm{R} \& \mathrm{D}$ in order to be the first to develop an innovation and then apply for patent rights, the winner rules out the possibility of the competitor's success through a similar technology (patent race models, such as Loury [1979], study this effect). In this setting, an increase in a firm's R\&D efforts increases the probability of its own success, but lowers that of its rival, generating negative spillovers on investment (e.g., Crépon and Duguet [1997] estimate a negative effect of rival R\&D on a firm's R\&D). However, when the patent rights are not well defined or when the R\&D approach followed by the firms is very different, a firm may benefit from the other firm's knowledge stock accessed through public sources. Then, the rival's $R \& D$ effort produces a positive spillover on investment because a firm is more likely to create an innovation thanks to another firm's R\&D effort. For example, in the absorptive capacity literature, it is shown that 'knowledge spillovers' induce complementarities in firms' R\&D efforts (Cohen and Levinthal [1989]).

We consider a general reduced form for the profits obtained in the final output market. The downstream sector in firm $i$ obtains the gross profit $V^{i}\left(e_{i}, e_{j}\right)$ if the downstream sector in firm $i$ uses the technological improvements created by the upstream sector in firm $i$; otherwise, it obtains $\bar{V}^{i}\left(e_{j}\right) \equiv V^{i}\left(0, e_{j}\right)$, which does not depend on the technological improvements made by the upstream sector $i$. Expressions $V^{i}\left(e_{i}, e_{j}\right)$ and $\bar{V}^{i}\left(e_{j}\right)$ may depend on the rival's R\&D effort, to allow for firm $i$ to experience spillovers in the production stage. As with the spillovers on investment, spillovers on production can also be positive or negative. Several papers consider positive spillovers on production by defining knowledge spillovers as the decrease in production costs because of the $R \& D$ investment emanating from other firms (e.g., Spence [1984], d'Aspremont and 
Jacquemin [1988], Bernstein and Nadiri [1989]). However, there are situations in which spillovers on production are negative because an innovation from a rival can increase the production cost of the firm. Consider an innovation that allows the rival to improve its product quality significantly at the same production cost. If the firm wants to stay in the market (or retain its market share), it may be under pressure to produce a similar quality, which would involve a higher marginal cost. Similarly, an innovation may allow the rival to address some employees' demands or some consumers' environmental concerns, which would increase the production cost of the firm to meet the same standard.

Thus, in the final stage of the game, when firm $i$ uses the technology of its upstream sector, firm $i$ 's net profit is

$$
\Pi^{i}\left(e_{i}, e_{j}\right) \equiv V^{i}\left(e_{i}, e_{j}\right)-I^{i}\left(e_{i}, e_{j}\right) .
$$

Summarizing, we analyze the three-stage game where:

- In the first stage, firms simultaneously and noncooperatively determine their organizational structures: vertically separated or integrated.

- In the second stage, the two upstream sectors simultaneously and noncooperatively choose their own R\&D effort $e_{i}(i=1,2)$.

- In the third stage, the downstream sectors compete in the final good market.

We assume that values $V^{i}\left(e_{i}, e_{j}\right)$ and $I^{i}\left(e_{i}, e_{j}\right)$ that firm $i$ obtains in the Nash equilibrium of the third stage, for $i=1,2$, satisfy the following assumptions:

(A1) $V^{i}\left(e_{i}, e_{j}\right)$ and $I^{i}\left(e_{i}, e_{j}\right)$ are twice continuously differentiable with respect to their own R\&D effort,

(A2) $V^{i}\left(e_{i}, e_{j}\right)$ is increasing in its own effort in R\&D: $V_{i}^{i}\left(e_{i}, e_{j}\right) \equiv \partial V^{i}\left(e_{i}, e_{j}\right) / \partial e_{i}>0$,

(A3) $I^{i}\left(e_{i}, e_{j}\right)$ is increasing and convex in its own R\&D effort: $I_{i}^{i}\left(e_{i}, e_{j}\right) \equiv \partial I^{i}\left(e_{i}, e_{j}\right) / \partial e_{i}>0, I_{i i}^{i}\left(e_{i}, e_{j}\right) \equiv \partial^{2} I^{i}\left(e_{i}, e_{j}\right) / \partial e_{i}^{2} \geq 0$, and

(A4) $\Pi^{i}\left(e_{i}, e_{j}\right)$ is concave in its own R\&D effort: $\Pi_{i i}^{i}\left(e_{i}, e_{j}\right) \equiv \partial^{2} \Pi^{i} / \partial e_{i}^{2}<0$.

For illustrative purposes, in the examples of Section V, we present particular functional forms of $V^{i}\left(e_{i}, e_{j}\right)$ and $I^{i}\left(e_{i}, e_{j}\right)$, by assuming that in the final good market, standard Cournot competition exists, and considering markets with different characteristics in terms of demand, spillovers, and bargaining power in the case of vertical separation. 


\section{GENERAL ANALYSIS}

First, we study the second stage decision for the two possible organizational forms that a firm can adopt. We obtain a firm's best response function when it is vertically integrated, and when it is vertically separated. Note that firm $i$ 's best response function does not depend on firm $j$ 's organizational form, only on firm $j$ 's R\&D investment. Of course, the equilibrium decision of firm $i$ in the R\&D stage will depend on the organizational structures of both firms.

Second, we investigate the basic properties of the iso-profit curve in the effort space and the investment reaction function. Then, using the characteristics of these functions, we classify the market structures into four cases and obtain Theorem 1.

\section{IV(i). Best Response Function of a Vertically Integrated Firm}

When firm $i$ is vertically integrated, the two sectors in firm $i$ are organized as one entity and they make the R\&D decisions together. The first-order condition of the maximization of $\Pi^{i}\left(e_{i}, e_{j}\right)$ with respect to $e_{i}$ is

$$
\Pi_{i}^{i}\left(e_{i}, e_{j}\right)=V_{i}^{i}\left(e_{i}, e_{j}\right)-I_{i}^{i}\left(e_{i}, e_{j}\right)=0 .
$$

From Equation 2, and assuming that the solution is interior, we can obtain the best response function of firm $i$ to any $\mathrm{R} \& \mathrm{D}$ effort of the rival that we denote $e_{i}^{I}\left(e_{j}\right)$, where the superscript refers to the type of organizational structure (here, Integration).

\section{IV(ii). Best Response Function of a Vertically Separated Firm}

When firm $i$ is vertically separated, the two sectors negotiate a lump-sum transfer $F_{i}$ from the downstream to the upstream sector in firm $i$. Because the agreement is negotiated after the $\mathrm{R} \& \mathrm{D}$ effort takes place, the $\mathrm{R} \& \mathrm{D}$ cost is sunk. If the negotiation succeeds, the upstream sector's profit is $F_{i}-I^{i}\left(e_{i}, e_{j}\right)$ and the downstream sector's profit is $V^{i}\left(e_{i}, e_{j}\right)-F_{i}$. If the negotiation fails, then the upstream sector's profit is $-I^{i}\left(e_{i}, e_{j}\right)$ and the downstream sector's profit is $\bar{V}^{i}\left(e_{j}\right)$. Thus, if the negotiation succeeds, the net surplus of the negotiation is $V^{i}\left(e_{i}, e_{j}\right)-\bar{V}^{i}\left(e_{j}\right)$.

We assume that, given $\left(e_{i}, e_{j}\right), F_{i}$ is the outcome of a (possibly asymmetric) Nash bargaining where the bargaining power of the separated upstream sector in firm $i$ is $\beta^{i}$, with $\beta^{i} \in(0,1)$, exogenously given. ${ }^{7}$ Thus, the fixed fee $F_{i}$ is characterized by

${ }^{7} \beta^{i}$ is likely to be large if the upstream sector is more important than the downstream sector in terms of size or weight in the production process. $\beta^{i}$ is also more likely to be large if the upstream sector is less competitive (e.g., there are fewer firms) than the downstream sector. 


$$
\begin{gathered}
\left(1-\beta^{i}\right)\left(F_{i}-0\right)=\beta^{i}\left(V^{i}\left(e_{i}, e_{j}\right)-F_{i}-\bar{V}^{i}\left(e_{j}\right)\right) \\
\text { or } \quad F_{i}=\beta^{i}\left(V^{i}\left(e_{i}, e_{j}\right)-\bar{V}^{i}\left(e_{j}\right)\right) .
\end{gathered}
$$

Anticipating the terms of the agreement, firm $i$ 's upstream sector maximizes the following expression with respect to $e_{i}$ :

$$
F_{i}-I^{i}\left(e_{i}, e_{j}\right)=\beta^{i}\left(V^{i}\left(e_{i}, e_{j}\right)-\bar{V}^{i}\left(e_{j}\right)\right)-I^{i}\left(e_{i}, e_{j}\right)
$$

The maximization problem is equivalent to

$$
\max _{e_{i}} \beta^{i} V^{i}\left(e_{i}, e_{j}\right)-I^{i}\left(e_{i}, e_{j}\right)
$$

The functional form differs from that in which firm $i$ is integrated. ${ }^{8}$ The coefficient of $V^{i}\left(e_{i}, e_{j}\right)$ is $\beta^{i}$ in the separation case, while it is 1 in the integration case. Given that $\beta^{i}<1$, the incentive of a separated upstream sector to invest in $R \& D$ is weaker than that of an integrated firm.

The first-order condition of the previous maximization in (3) is

$$
\beta^{i} V_{i}^{i}\left(e_{i}, e_{j}\right)-I_{i}^{i}\left(e_{i}, e_{j}\right)=0 .
$$

If the solution is interior, Equation 4 provides the best response function $e_{i}^{S}\left(e_{j}\right)$ of a vertically separated firm $i$ to any investment level of the rival (superscript indicates Separation).

By comparing (2) and (4), we obtain the following lemma.

Lemma 1. Given $e_{j}, e_{i}^{S}\left(e_{j}\right)$ is always lower than $e_{i}^{I}\left(e_{j}\right)$. In addition, $e_{i}^{I}\left(e_{j}\right)-e_{i}^{S}\left(e_{j}\right)$ decreases with $\beta^{i}$.

Lemma 1 states that vertical separation is a credible commitment to investing less in R\&D.

\section{IV(iii). $\quad R \& D$ Equilibrium}

The equilibrium R\&D decisions $\left(e_{1}^{*}, e_{2}^{*}\right)$ are the ones that satisfy $e_{1}^{B R}\left(e_{2}^{*}\right)=e_{1}^{*}$ and $e_{2}^{B R}\left(e_{1}^{*}\right)=e_{2}^{*}$, where $e_{i}^{B R}\left(e_{j}\right)=e_{i}^{I}\left(e_{j}\right)$ or $e_{i}^{B R}\left(e_{j}\right)=e_{i}^{S}\left(e_{j}\right)$ depending on whether firm $i$ is vertically integrated or separated, for $i, j=1,2$ and $j \neq i$.

\footnotetext{
${ }^{8}$ What matters for our result is how a firm can credibly commit to underinvest in R\&D. Adopting a vertical separation is a credible option, easy to verify by the rival. Integration with less than fully centralized decision-making and accountability, causing the upstream sector to be less than fully accountable for downstream benefits from R\&D, could also be an option if those features are verifiable for the rival. In this sense, we could also interpret $\beta^{i}$ as the preestablished share of the final profit. If the upstream sector in firm $i$ gains $\beta^{i}\left(V^{i}\left(e_{i}, e_{j}\right)-\bar{V}^{i}\left(e_{j}\right)\right)$, which is contingent on the $\mathrm{R} \& \mathrm{D}$ outcomes, from the $\mathrm{R} \& \mathrm{D}$ input, $\beta^{i}$ is interpreted as the profit-sharing ratio of the upstream sector in firm $i$.
} 


\section{IV(iv). Iso-Profit Curve and Reaction Function}

As we have seen previously, vertical separation induces a distortion in the incentive to invest in $\mathrm{R} \& \mathrm{D}$, whenever the bargaining power of the upstream sector is smaller than 1 . To understand whether this distortion is profitable for the firm, that is, whether vertical separation is preferable, it is useful to analyze the slope of the iso-profit curve and the slope of the reaction function $e_{i}^{I}\left(e_{j}\right)$ at the equilibrium $\left(e_{1}^{*}, e_{2}^{*}\right)$.

First, we examine the properties of the firms' iso-profit curves. For a certain profit level $a \geq 0$, the iso-profit curve of firm $i$ is defined as $\left\{\left(e_{1}, e_{2}\right) \in \mathbb{R}_{+}^{2}: \Pi^{i}\left(e_{1}, e_{2}\right)=a\right\}$. Totally differentiating $\Pi^{i}(e)$, we obtain

$$
\Pi_{i}^{i} d e_{i}+\Pi_{j}^{i} d e_{j}=0 .
$$

From this expression, we compute the slope of the iso-profit curve:

$$
\frac{d e_{j}}{d e_{i}}=-\frac{\Pi_{i}^{i}}{\Pi_{j}^{i}} .
$$

Note that $\Pi_{i}^{i}>0$ for $e_{i}<e_{i}^{I}\left(e_{j}\right)$ and $\Pi_{i}^{i}<0$ for $e_{i}>e_{i}^{I}\left(e_{j}\right)$.

The second derivative of the iso-profit curve is

$$
\frac{d\left(\frac{d e_{j}}{d e_{i}}\right)}{d e_{i}}=-\frac{\Pi_{i i}^{i} \Pi_{j}^{i}-\Pi_{i}^{i} \Pi_{j i}^{i}}{\left(\Pi_{j}^{i}\right)^{2}} .
$$

By (A4) we know that $\Pi_{i i}^{i}<0$. Moreover, at the optimal effort $e_{i}^{I}\left(e_{j}\right)$ chosen by an integrated firm $i, \Pi_{i}^{i}\left(e_{i}^{I}, e_{j}\right)=0$, Therefore, by (5), at this best reply, the iso-profit curve of firm $i$ is concave with respect to $e_{i}$ if and only if $\Pi_{j}^{i}<0$; and it is convex if and only if $\Pi_{j}^{i}>0$. The convexity of firm $i$ 's isoprofit curve is equivalent to the fact that firm $j$ 's investments benefit firm $i$. Conversely, the concavity of firm $i$ 's iso-profit is equivalent to having firm $j$ 's investments harm firm $i$.

Second, to find the slope of the reaction function $e_{i}^{I}\left(e_{j}\right)$, we substitute $e_{i}$ by $e_{i}^{I}\left(e_{j}\right)$ into (2) and differentiate the expression with respect to $e_{j}$ to obtain

$$
\begin{gathered}
\frac{\partial^{2} \Pi^{i}\left(e_{i}, e_{j}\right)}{\partial e_{i}^{2}} \frac{d e_{i}^{I}\left(e_{j}\right)}{d e_{j}}+\frac{\partial^{2} \Pi^{i}\left(e_{i}, e_{j}\right)}{\partial e_{i} \partial e_{j}}=0 \\
\text { or } \quad \frac{d e_{i}^{I}\left(e_{j}\right)}{d e_{j}}=-\frac{\Pi_{i j}^{i}\left(e_{i}, e_{j}\right)}{\Pi_{i i}^{i}\left(e_{i}, e_{j}\right)} .
\end{gathered}
$$

Because the denominator of the latter fraction is negative, we see that 


$$
\frac{d e_{i}^{I}\left(e_{j}\right)}{d e_{j}} \gtreqless 0 \text { iff } \Pi_{i j}^{i}(e) \gtreqless 0 .
$$

Thus, the cross-partial derivative of the net profit is the key factor related to the slope of the reaction function. Using a similar argument, we can study the slope of the reaction function under separation, $e_{i}^{S}\left(e_{j}\right)$ :

$$
\frac{d e_{i}^{S}\left(e_{j}\right)}{d e_{j}} \gtreqless 0 \text { iff } \Pi_{i j}^{i}(e) \gtreqless 0 .
$$

The two inequalities in (6) and (7) mean that firms' investment levels are strategic substitutes if and only if the cross-partial derivative of the net profit is negative. Furthermore, firms' investment levels are strategic complements if and only if the cross-partial derivative of the net profit with respect to the $\mathrm{R} \& \mathrm{D}$ efforts is positive.

To clarify the relationship between spillovers and the slope of the reaction functions, $e_{i}\left(e_{j}\right)$, consider a scenario without spillovers on investment, that is, without spillovers via $I^{i}\left(e_{i}, e_{j}\right)$. Here, the cross-partial derivative of the profit with respect to the $\mathrm{R} \& \mathrm{D}$ efforts only depends on their effect on net profits via the market competition and the cost function that may present spillovers on production (e.g., d'Aspremont and Jacquemin [1988]). Now, we add R\&D spillovers on investment to this scenario. Positive (resp. negative) R\&D spillovers on investment (adding a positive (resp. negative) term to the effect via net profits) are more likely to make the slope of the reaction function $e_{i}\left(e_{j}\right)$ positive (resp. negative). However, the existence of R\&D spillovers on investment is not a sufficient determinant of the slope of the reaction function $e_{i}\left(e_{j}\right)$ when there are spillovers on production.

\section{IV(v). Possible Cases}

From the previous analysis, four cases can arise depending on the signs of $\Pi_{j}^{i}$ and $\Pi_{i j}^{i}$. To illustrate the classification, and to see how it may affect the choice of the organizational structure at stage 1, we present four graphical examples in Figure 1.

We discuss the four cases separately.

Case 1. The iso-profit curve of each firm is convex with respect to its R\&D effort and the reaction function of each firm is downward sloping.

In this case, the rival's investment helps the firm (i.e., it increases the convexity of the iso-profit curves), and this effect is stronger if the spillovers on production are high. Furthermore, R\&D efforts are strategic substitutes. Therefore, at stage 1, each firm faces the following trade-off. On the one 
hand, a high R\&D effort directly results in a better position in the market. Such a high R\&D effort can be achieved by adopting vertical integration (Lemma 1). On the other hand, each firm can increase the rival's R\&D investment by committing to a lower R\&D effort (strategic substitution). Such beneficial commitment is attainable by adopting vertical separation.

The trade-off between the two effects will depend on (i) the size of the spillover effects and (ii) the bargaining power that affects the shift of the reaction function under vertical separation. For the first aspect, we should expect vertical integration if those spillovers are low and vertical separation if they are high. For the second aspect, we should expect vertical integration if the

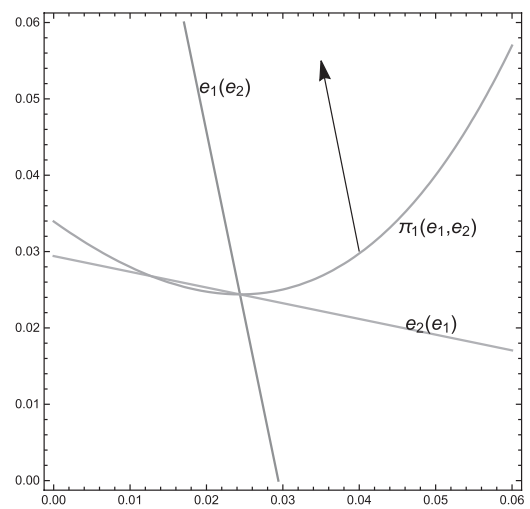

1. Convex and downward

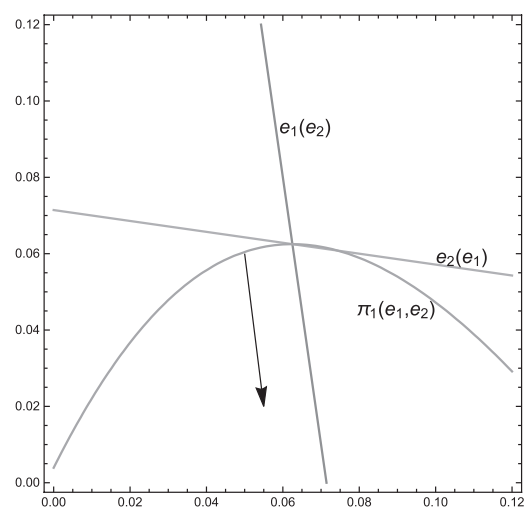

3. Concave and downward

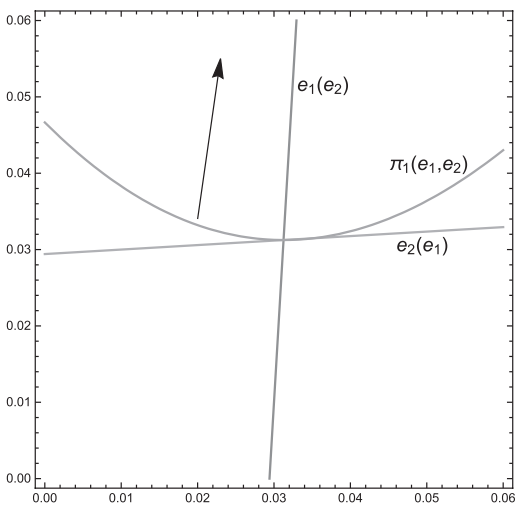

2. Convex and upward

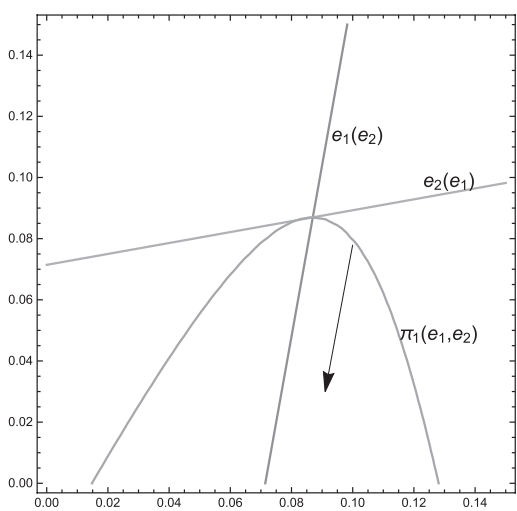

4. Concave and upward

Figure 1

Iso-Profit Curves and Reaction Functions in the Effort Space Defining the Four Possible Cases Notes: Horizontal axis: $e_{1}$; Vertical axis: $e_{2}$. The arrow indicates the direction of increasing profit for firm 1. [Colour figure can be viewed at wileyonlinelibrary.com]

(C) 2022 The Authors. The Journal of Industrial Economics published by Editorial Board of Journal of Industrial Economics and John Wiley \& Sons Ltd. 
bargaining power of the upstream sector is weak, and vertical separation if it is strong.

For the sake of argument, let us consider a scenario where $\beta^{i}=1$. In this case, separation and integration are equivalent. When $\beta^{i}$ marginally decreases from $\beta^{i}=1$, the cost of vertical separation in terms of the direct effect is negligible because the loss from lowering firm $i$ 's R\&D level is marginal around the neighborhood of the optimal $\mathrm{R} \& \mathrm{D}$ effort under vertical integration, $\beta^{i}=1$. Contrary to the marginal loss, the strategic gain from vertical separation has a first-order effect because vertical separation induces the rival to invest more, helping firm $i$ because of the convex iso-profit curve. However, as the value of $\beta^{i}$ decreases, the cost of vertical separation increases because the R\&D effort under vertical separation diverges significantly from the optimal R\&D level under vertical integration. As a result, the direct cost of vertical separation outweighs the strategic benefit of vertical separation when $\beta^{i}$ is small.

Case 2. The iso-profit curve of each firm is convex with respect to its $R \& D$ effort and the reaction function of each firm is upward sloping.

Here, the rival's $R \& D$ effort helps the firm, and $R \& D$ levels are strategic complements. Each firm directly profits from its R\&D effort and also benefits indirectly, because investing more induces its rival to invest more. In this situation, vertical integration is superior.

Case 3. The iso-profit curve of each firm is concave with respect to its $R \& D$ effort and the reaction function of each firm is downward sloping.

If a rival's $R \& D$ investment harms the firm and $R \& D$ efforts are strategic substitutes, then the direct and indirect effects of investment will make aggressive investment attractive for firms. Such an aggressive investment is attainable by adopting vertical integration at stage 1 .

Case 4. The iso-profit curve of each firm is concave with respect to its $R \& D$ effort and the reaction function of each firm is upward sloping.

In this case, the rival's $R \& D$ investment harms the firm, and $R \& D$ efforts are strategic complements. Then, a higher investment level has a direct effect on the firm's competitiveness but induces the rival to invest more. The latter indirect effect harms the firm. As in Case 1, there are two forces at work, and the intuition follows the same lines. The decision of each firm regarding vertical separation or integration at stage 1 depends on (i) whether the degree of strategic complementarity is high or low, and (ii) whether the upstream sector's bargaining power is weak or strong. For high enough values of $\beta^{i}$, the optimal decision is to vertically separate, while for low values of $\beta^{i}$, the optimal organization is integration. 
We summarize the above discussion in the following theorem (the proof is relegated to the Appendix).

Theorem 1. In Cases 2 and 3, regardless of the rival firm's vertical structure, a firm prefers vertical integration to vertical separation. In Case 1 (resp. Case 4), there exists a $\hat{\beta}_{k}^{i} \in(0,1)\left(\right.$ resp. $\left.\tilde{\beta}_{k}^{i} \in(0,1)\right)$ such that for firm $i$, vertical separation is preferable if $\beta^{i} \geq \widehat{\beta}_{k}^{i}$ (respectively, $\beta^{i} \geq \tilde{\beta}_{k}^{i}$ ) and the organizational structure of firm $j$ is $k \in\{I, S\}$, where $i, j=1,2, j \neq i$, and $I$ and $S$ represent vertical Integration and Separation.

Note that for Case 1 (resp. Case 4), Theorem 1 shows the existence of $\beta^{1}<1$ at which firm 1 prefers vertical separation to integration under assumptions (A1) to (A4). However, for the existence of the unique threshold value $\widehat{\beta}_{k}$ (resp. $\tilde{\beta}_{k}^{1}$ ), a more demanding condition on the profit function is needed to ensure the global convexity of firm 1's iso-profit curves. This condition is guaranteed under the assumption $\Pi_{i i}^{i} \Pi_{j}^{i}<\Pi_{i}^{i} \Pi_{j i}^{i}$.

We can compare our taxonomy with the one proposed by Fudenberg and Tirole [1984]. One dimension, the slope of the reaction curves, is the same. For the other dimension, we can interpret the cases where the R\&D investment of a firm helps the rival as a case where the investment makes the firm that invests 'soft,' and the cases where the R\&D investment of a firm harms the rival as a case where the investment makes the firm 'tough."

\section{IV(vi). Possibilities of Nonexclusive Vertical Chains}

Although we have considered exclusive vertical chains, let us briefly discuss a scenario in which a separated upstream sector in a vertical chain can supply to the downstream sector of the rival vertical chain (we call this the 'dual supply capability'). Below, we show that the possibility of a nonexclusive relationship does not change the R\&D investment incentives of the two upstream sectors in the revised setting.

The game discussed here also has three stages. In the first stage, firms simultaneously and noncooperatively determine their organizational structures: vertically separated or integrated. In addition to the decision, if a firm vertically separates, it also determines whether the relationship between the upstream and downstream sectors is exclusive or not. ${ }^{10}$ The exclusive relationship is the same as that in the main model. The nonexclusive relationship means that the upstream sector can supply to the competing

${ }^{9}$ Using Fudenberg and Tirole's terminology, Case 1 corresponds to 'lean and hungry,' Case 2 to 'fat cat,' Case 3 to 'top dog,' and Case 4 to 'puppy dog.' However, these very intuitive names (inspired by a situation where the incumbent prevents or accommodates an entry) are not well suited for our setup.

${ }_{10}$ Milliou [2008] considers a downstream monopoly model with an endogenous choice of exclusive vertical relationship. 
downstream sector in the rival vertical chain. In the second stage, each of the two upstream sectors simultaneously and noncooperatively chooses their own R\&D effort $e_{i}(i=1,2)$. Assume that a separated upstream sector incurs adjustment costs in terms of effort unit, $\tau$, to supply to the downstream sector of the rival vertical chain, because of the firm-specific relationship. Then, after the upstream sectors make their R\&D investments, if firm $i(i=1,2)$ vertically separates, the two sectors in firm $i$ negotiate a lump-sum transfer $F_{i}$ from the downstream to the upstream sector in firm $i$. Note that if both firms vertically separate, the disagreement profit of the downstream sector in firm $i$ differs from that in the main model because it can potentially procure from the upstream sector in the competing vertical chain. The disagreement profit of this downstream sector in firm $i$ is $\bar{V}^{i}\left(e_{j}\right)=V^{i}\left(e_{j}-\tau, e_{j}\right)-f_{i}$ or $\bar{V}^{i}\left(e_{j}\right)=V^{i}\left(0, e_{j}\right)$, which reflects the effort, $e_{j}$, the adjustment cost of the upstream sector in firm $j, \tau$, and an off-path lump-sum payment for the upstream sector $j, f_{i}$. We assume that $\tau$ is not small enough such that monopolization of the upstream market is not profitable for separated upstream sectors. Finally, each of the downstream sectors competes with its rivals in the final good market by using their available technological improvements.

Because both $V^{i}\left(e_{j}-\tau, e_{j}\right)-f_{i}$ and $V^{i}\left(0, e_{j}\right)$ are independent of $e_{i}$, the maximization problem of the upstream sector of firm $i(i=1,2)$ in the second stage is the same as that in the main model (see (3)). Therefore, the possibility of a nonexclusive relationship does not change the R\&D investment incentives of the two upstream sectors.

\section{ILLUSTRATING EXAMPLES}

Here, we further investigate the equilibrium organizational structures using parametric examples. To illustrate the analysis as a function of the nature of the spillovers on investment and on production, we consider a market where two identical firms compete in quantities in a market with the following inverse demand function:

$$
p=\frac{3}{2}-q_{1}-q_{2}
$$

where $q_{i}$ is the quantity supplied by firm $i(i=1,2)$. We allow for different combinations of $\mathrm{R} \& \mathrm{D}$ spillovers, and analyze the equilibrium of the threestage game.

The $\mathrm{R} \& \mathrm{D}$ process produces a reduction in the marginal cost. As a result of the $\mathrm{R} \& \mathrm{D}$, the marginal cost of firm $i, c_{i}$, is given as

$$
c_{i}\left(e_{i}, e_{j}\right)=1-\left(e_{i}+\theta e_{j}\right),
$$


where $e_{i}$ and $e_{j}$ are the R\&D effort of firms $i$ and $j(i, j=1,2, j \neq i)$, and $\theta \in[0,1]$ is an exogenous parameter. The first term of $c_{i}\left(e_{i}, e_{j}\right)$ is an $e x$ ante marginal cost level (normalized to 1 ); the second term is the degree of marginal cost reduction, which includes the degree of $R \& D$ spillovers on production, measured by $\theta$. Note that $c_{i}\left(e_{i}, e_{j}\right)$ in (9) is essentially equivalent to the expression for the marginal cost in d'Aspremont and Jacquemin [1988].

We assume that the $\mathrm{R} \& \mathrm{D}$ investment cost of firm $i$ is given as

$$
I^{i}\left(e_{i}, e_{j}\right)=2 e_{i}^{2}-\delta e_{i} e_{j},
$$

where $\delta \in[-1,1]$ is an exogenous parameter measuring the spillovers on investment.

In these scenarios defined by $(\theta, \delta)$, the gross profit of firm $i$ in the second stage is given as

$$
V^{i}\left(e_{i}, e_{j}\right)=\frac{\left(3 / 2+c_{j}\left(e_{i}, e_{j}\right)-2 c_{i}\left(e_{i}, e_{j}\right)\right)^{2}}{9} .
$$

The net profit of firm $i$ in the first stage is given as

$$
\begin{aligned}
\Pi^{i}\left(e_{i}, e_{j}\right) & =V^{i}\left(e_{i}, e_{j}\right)-I^{i}\left(e_{i}, e_{j}\right) \\
& =\frac{\left(1 / 2-\left(e_{j}+\theta e_{i}\right)+2\left(e_{i}+\theta e_{j}\right)\right)^{2}}{9}-\left(2 e_{i}^{2}-\delta e_{i} e_{j}\right) .
\end{aligned}
$$

Before presenting parametric examples of the cases listed in Section $\mathrm{IV}(\mathrm{v})$, let us consider the situation where there is no spillover in any stage (on production or on investment), that is, $\theta=\delta=0$. Without spillovers, the iso-profit curve of each firm is concave with respect to its $R \& D$ effort, and the reaction function of each firm is downward sloping, a situation of strategic substitutes. This scenario belongs to Case 3, where for any bargaining power of separated upstream sectors, the firms vertically integrate in equilibrium.

The Shapes of Iso-Profit Curves and Reaction Functions. Following the classification in Section IV(v), in what follows we discuss the decisions of the two symmetric firms on the scenarios generated by the parameter values summarized in Table II.

In these four scenarios, we will consider symmetric firms, both in terms of the nature and the magnitude of the spillovers $\theta$ and $\delta$ (which define the case a firm is facing) and with respect of their bargaining power. After we explain the four cases, we briefly discuss what happens if the spillovers the firms 
TABLE II

Parametric Examples for the Four Cases

\begin{tabular}{llc}
\hline Example of & $\theta$ & $\delta$ \\
\hline Case 1 & 1 & $\delta<-2 / 9$ \\
Case 2 & 1 & $-2 / 9 \leq \delta \leq 0$ \\
Case 3 & 0 & $0 \leq \delta \leq 4 / 9$ \\
Case 4 & 0 & $4 / 9<\delta$ \\
\hline
\end{tabular}

generate are not the same. Then in Section V(iii), we present in one of the scenarios the equilibrium organizational structure for any $\left(\beta^{1}, \beta^{2}\right)$ to illustrate the effect of the bargaining power.

\section{V(i). Parametric Examples of Cases 1 and $2(\theta=1)$}

We first consider the extreme case in which $R \& D$ spillovers on production are positive and large, $\theta=1$, for example, because $R \& D$ outcomes stem from the two firms' open innovation. In addition, we assume that R\&D spillovers on investment are negative, implying that the firm R\&D effort gives an important disadvantage to the rival. As an example of this combination of R\&D spillovers on production and R\&D spillovers on investment, one can think of an open innovation that requires a scarce labor force (e.g., programmers with high IT skills). In this scenario, innovation has a public good nature, and at the same time, it increases the $R \& D$ costs of the rival through the labor market competition for high-skill programmers. We illustrate that Case 1 emerges when the negative $\mathrm{R} \& \mathrm{D}$ spillovers on investment are important. In contrast, when the negative spillovers on investment are very small, then the situation belongs to Case 2 .

From (9) and (10), the marginal cost of production and R\&D cost of firm $i$ are given as

$$
c_{i}=1-\left(e_{i}+e_{j}\right), \quad I^{i}\left(e_{i}, e_{j}\right)=2 e_{i}^{2}-\delta e_{i} e_{j},
$$

where we assume $\delta \leq 0$. In scenario (13), firm $j$ 's R\&D effort improves the efficiencies of firms $j$ and $i$ equally. In other words, the cost-reducing efforts of the firms are a public good. Furthermore, there are negative spillovers on investment, $\delta \leq 0$, in such a way that the R\&D effort of a firm increases the $\mathrm{R} \& \mathrm{D}$ cost of the rival.

For any $\delta \leq 0$, the iso-profit curve of firm $i$ is convex with respect to $e_{i}$. In contrast, the slope of the reaction function depends on the magnitude of the negative spillovers on investment, $\delta$. If the magnitude is strong (resp. weak), in particular, if $\delta<-2 / 9$ (resp. $-2 / 9 \leq \delta \leq 0$ ), the reaction function is 
downward (upward) sloping. ${ }^{11}$ A substantially negative $\delta$ means that the substitutability of the R\&D efforts is large, implying that the R\&D efforts of the firms are strategic substitutes.

When the degree of negative spillovers on investment is significant, the market structure belongs to Case 1. As shown in Theorem 1, the equilibrium vertical structure depends on the bargaining power $\beta\left(\beta=\beta^{1}=\beta^{2}\right)$ in case of separation. If $\beta$ is sufficiently close to 1 , the combination of the positive spillovers on production and the negative spillovers on investment induces the firms to adopt vertical separation as a credible commitment to engage in lower R\&D efforts, which cause the rivals to invest more.

When the degree of negative spillovers on investment is small, say, for instance, $\delta=0$, then the situation with perfect spillovers on production $\grave{a}$ la d'Aspremont and Jacquemin [1988] belongs to Case 2. In this case, for any bargaining power in the case of separation, the firms adopt vertical integration in equilibrium. Their $\mathrm{R} \& \mathrm{D}$ efforts translate into a universal reduction in production costs, and $\mathrm{R} \& \mathrm{D}$ investment levels are strategic complements. The firms employ vertical integration to commit to investing more credibly.

Proposition 1. When the market is defined by Equations 8 and 13, and for sufficiently large $\beta=\beta^{1}=\beta^{2}$, then in equilibrium, the firms adopt vertical separation if $\delta<-2 / 9$; otherwise, they select vertical integration.

\section{V(ii). Parametric Examples of Cases 3 and $4(\theta=0)$}

Now we consider situations where there are no R\&D spillovers on production (a setting with strong patent protection of the innovation, and firms have different production processes) and the spillovers on investment are positive. For example, imagine that the firms' production technologies are considerably different, and they use different production processes so that a firm cannot benefit from the rival's innovation. Nevertheless, a firm can profit from the rival's R\&D ideas and effort to improve its own R\&D process. Then, for low enough positive spillovers on investment, the situation

11 The net profit of firm $i$ is

$$
\Pi_{i}=\frac{\left(1+2 e_{i}+2 e_{j}\right)^{2}}{36}-\left(2 e_{i}^{2}-\delta e_{i} e_{j}\right)
$$

The first-order and cross-partial derivatives are

$$
\frac{\partial \Pi_{i}}{\partial e_{i}}=\frac{1-34 e_{i}+(2+9 \delta) e_{j}}{9}, \quad \frac{\partial^{2} \Pi_{i}}{\partial e_{i} \partial e_{j}}=\frac{2+9 \delta}{9} .
$$

The cross-partial derivative is negative (resp. positive) if and only if $\delta<-2 / 9$ (resp. $-2 / 9<\delta \leq 0)$. 
belongs to Case 3 , while Case 4 emerges when the positive R\&D spillovers on investment are strong enough.

From (9) and (10), the marginal cost and investment cost of firm $i$ are given as

$$
c_{i}=1-e_{i}, \quad I^{i}\left(e_{i}, e_{j}\right)=2 e_{i}^{2}-\delta e_{i} e_{j},
$$

where now we assume $\delta \geq 0$, in such a way that firm $j$ s R\&D effort affects only its marginal production cost but does not affect the marginal production cost of firm $i$. In other words, the cost-reducing efforts of the firms are private goods. Second, there are positive spillovers on investment, $\delta>0$, in such a way that the R\&D effort of a firm decreases the R\&D investment cost of the rival.

In all these situations, that is, for all $\delta \geq 0$, the iso-profit curve of firm $i$ is concave with respect to $e_{i}$. As in Section V(i), the slope of the reaction function depends on the magnitude of the positive spillovers on investment, measured by $\delta$. If the positive spillovers are weak (resp. strong), in particular $0 \leq \delta \leq 4 / 9$ (resp. $\delta>4 / 9$ ), the reaction function is downward (resp. upward) sloping. ${ }^{12} \mathrm{~A}$ higher $\delta$ indicates that the complementarity of the firms' R\&D efforts through the positive spillovers is larger. This relation implies that the complementarity overrides the substitutability induced by market competition. As a result, the firms' R\&D efforts become strategic complements for high values of $\delta$.

When positive spillovers on investment are small, say, for example, $\delta=0$ (standard Cournot competition without any spillovers), the situation belongs to Case 3. Vertical separation merely diminishes the R\&D investment level of the separated firm, which weakens its competitiveness but strengthens the rival's competitiveness.

When the positive R\&D spillovers on investment are significant, the situation belongs to Case 4 . The considerable spillovers on investment mean that a decrease in $e_{i}$ induces a reduction in $e_{j}$. As indicated in Theorem 1 , the equilibrium vertical structure depends on the bargaining power $\beta$ $\left(\beta=\beta^{1}=\beta^{2}\right)$ in case of separation. For a sufficiently large $\beta$, the combination of the positive spillovers on investment and the effect through the Cournot market interaction induces the firms to adopt vertical separation, because choosing a vertically separated organization works as a credible commitment to engage in lower $\mathrm{R} \& \mathrm{D}$ efforts, which induces the rival to invest less.

12 The net profit of firm $i$ is

$$
\Pi_{i}=\frac{\left(1+4 e_{i}-2 e_{j}\right)^{2}}{36}-\left(2 e_{i}^{2}-\delta e_{i} e_{j}\right)
$$

The first-order and cross-partial derivatives are

$$
\frac{\partial \Pi_{i}}{\partial e_{i}}=\frac{2-28 e_{i}-(4-9 \delta) e_{j}}{9}, \quad \frac{\partial^{2} \Pi_{i}}{\partial e_{i} \partial e_{j}}=-\frac{4-9 \delta}{9} .
$$

The cross-partial derivative is negative (resp. positive) if and only if $\delta<4 / 9$ (resp. $4 / 9<\delta \leq 1$ ). 
Proposition 2. When the market is defined by Equations 8 and 14, and for sufficiently large $\beta=\beta^{1}=\beta^{2}$, then in equilibrium, the firms adopt vertical separation if $\delta>4 / 9$; otherwise, they choose vertical integration.

In sum, comparing the results obtained in Sections V(i) and V(ii), we conclude that (i) significantly positive spillovers on production with significantly negative spillovers on investment (Case 1) and (ii) significantly large positive spillovers on investment without spillovers on production costs (Case 4) lead to similar outcomes. In those situations, firms choose vertical separation if the bargaining power parameter in the case of separation is sufficiently large.

Additional Remarks. To complete the discussion, let us make two remarks. First, in the previous examples, firms are identical in all respects. It can be the case that the nature and the magnitude of the parameters representing $R \& D$ spillovers, $\theta$ and $\delta$, (which define the case a firm is facing) differ for firms 1 and 2.

Let us consider the same spillover structure as before,

$$
c_{i}=1-\left(e_{i}+\theta_{i} e_{j}\right) \quad \text { and } \quad I^{i}\left(e_{i}, e_{j}\right)=2 e_{i}^{2}-\delta e_{i} e_{j},
$$

assume that $\delta=-1 / 2$, and let us comment on three combinations of spillovers on production: symmetric medium and large spillovers, $\theta_{1}=\theta_{2}=1 / 2$ and $\theta_{1}=\theta_{2}=3 / 4$, and asymmetric spillovers (hence asymmetric firms) $\theta_{1}=3 / 4$ and $\theta_{2}=1 / 2$. $^{13}$

For $\theta_{1}=\theta_{2}=1 / 2$, both firms are in Case 3 , and both are better off adopting vertically integrated structures. For $\theta_{1}=\theta_{2}=3 / 4$, both firms are in Case 1 , and at least one of the firms has an incentive to vertically separate if $\beta^{i}>0.942(i=1,2)$. In the asymmetric case, $\theta_{1}=3 / 4$ and $\theta_{2}=1 / 2$, firm 1 is in Case 1 and the other firm is in Case 3. Firm 1 has an incentive to vertically separate if $\beta^{1}>0.939$, while firm 2 prefers to employ vertical integration. Hence, we expect that a firm that benefits from a higher spillover from the rival's $R \& D$ effort on its production is more likely to choose vertical separation if in addition there are negative spillovers on investment.

Second, Cohen et al. [2002] find that R\&D spillovers are significant and also that spillovers are greater in Japan than in the U.S. They identify the differences in patent policy as a key reason for greater R\&D spillovers in Japan, where there is an important strategic use of patents, particularly for negotiations. The finding in Cohen et al. [2002] supports the difference between the vertical structures in Japan and the U.S. because R\&D efforts are strategic substitutes. The asymmetric degrees of spillovers lead to different organizational strategies in Japan, with large spillovers (Case 1), and in the U.S., with lower spillovers (Case 3).

13 The Mathematica file used to derive the results in this remark is available upon request. 
Finally, we have framed the example in a market where firms compete in quantities. Note that one can obtain qualitatively similar results under price competition with the linear demand system (Dixit [1979], Singh and Vives [1984]). ${ }^{14}$

\section{V(iii). Generalized Values of $\beta^{i}$ in Case 1}

Which of the four cases that appears depends only on demand, and the production and R\&D cost parameters (including spillovers). In Cases 2 and 3, in which the two firms employ vertical integration to invest more, the value of $\beta^{i}$ does not matter in the decisions of vertical structure in equilibrium. In contrast, in Cases 1 and 4, in which vertical separation may work as a commitment device to invest less, the parameter $\beta^{i}$ is a critical parameter that influences the decisions of vertical separation.

To illustrate how the bargaining power affects the vertical structure, here we consider a market with $\theta=1, \delta=-1$, and any $\beta^{i} \in[0,1]$ and we check how the values of $\beta^{1}$ and $\beta^{2}$ influence the equilibrium vertical structure. Except for the relaxation of the two parameters $\beta^{i}$ and the imposition of $\delta=-1$, we use the same parameters as in Section V(i). Using a numerical analysis, we obtain Figure $2 .^{15}$

Result 1 summarizes Figure 2, where the functions $\beta_{S}^{j}\left(\beta^{i}\right)$ for $i, j=1,2$ are increasing and such that $\beta_{S}^{j}(1)=0.648$, and $\beta_{S}^{j}(0.629)=0.629$.

Result 1. When the market is defined by Equations 8 and 13, and for $\delta=-1$,

1. if $\beta^{i}>0.648$ and $\beta^{j}>\widehat{\beta}_{S}^{j}\left(\beta^{i}\right)$ for $i, j=1,2(j \neq i)$ where $\widehat{\beta}_{S}^{i}\left(\beta^{j}\right)$ for $i, j=1,2$ $(j \neq i)$ is in Figure 2, then the firms vertically separate (area $B$ in Figure 2);

2. if $\beta^{i}>0.648$ and $\beta^{j}<\hat{\beta}_{S}^{j}\left(\beta^{i}\right)$, then firm $i$ separates and firm $j$ integrates (areas $O_{i}(i=1,2)$ in Figure 2);

3. if $\widehat{\beta}_{S}^{i}\left(\beta^{j}\right) \leq \beta^{i} \leq 0.648$ for $\beta^{i}>0.629(i, j=1,2, j \neq i)$, there are two possible equilibria in which either the two firms separate or the two integrate (area $B N$ in Figure 2);

4. otherwise, in equilibrium, no firm separates (area $N$ in Figure 2).

Result 1 shows how the equilibrium organizational structure varies as a function of the values of bargaining power, $\left(\beta^{1}, \beta^{2}\right)$, in the case of separation.

14 In our model, we consider a lump-sum transfer within separated sectors in a vertical chain. The difference between price and quantity competition is weaker because in a vertical chain the wholesale price is always equal to the marginal cost (note that the price scheme is related to $t=0$ in Equation 1 in Chen and Sappington [2010]). In other words, the wholesale price of each vertical chain does not work as a strategic commitment to downstream behavior. Therefore, the strategic effect of vertical separation is diluted compared with the approach of the related works (e.g., Bonnano and Vickers [1988], Gupta [2008], Gupta and Loulou [1998]).

15 The Mathematica file used to derive Figure 2 is available upon request. 


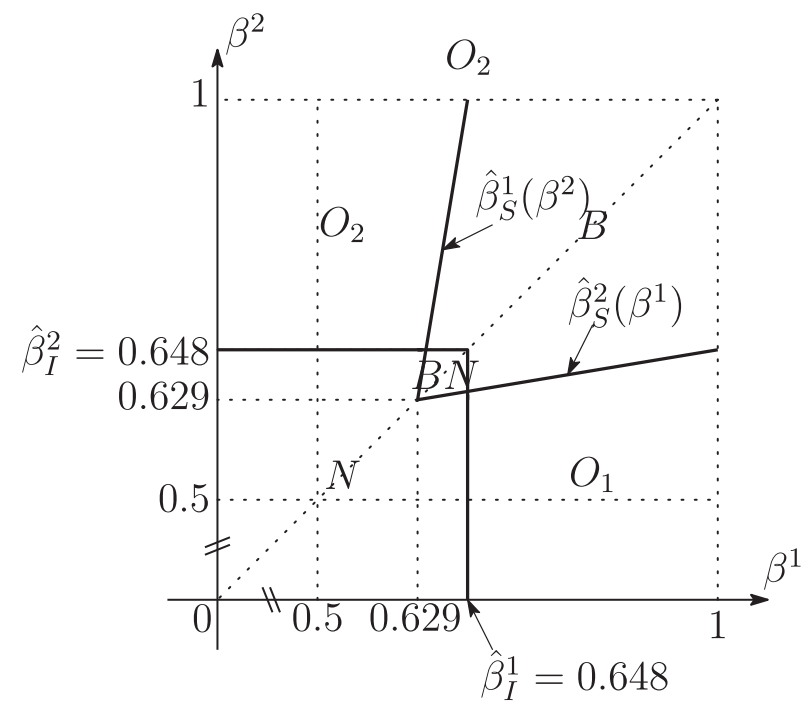

Figure 2

Equilibrium Vertical Structures under Case $1(\theta=1, \delta=-1)$

Notes: $B$ : Both separate; $O_{1}$ : Only firm 1 separates; $O_{2}$ : Only firm 2 separates; $B N$ : Both separate or No firm separates; $N$ : No firm separates. (The threshold curves $\widehat{\beta}_{S}^{l}\left(\beta^{j}\right)$ are not straight lines).

Part 2 of Result 1 , in particular, shows that when $\beta^{1}$ and $\beta^{2}$ are very different, asymmetric organizational structures arise. We apply the logic in Result 1 based on Case 1 to a reference scenario based on Case 4: the differences between the upstream sectors' bargaining powers may explain why different firms adopt different vertical organizations.

Result 1 is complementary to the explanation in Matsushima and Mizuno [2013] who show that vertical separation is more likely to appear in equilibrium if the bargaining power of independent complementary input suppliers is high. The existence of multiple suppliers is the key ingredient that leads to vertical separation in Matsushima and Mizuno [2013]. Contrary to their setting, we do not assume multiple inputs but formulate the interaction between upstream sectors in two competing vertical chains, and show that technological spillover can be a driving force of vertical separation. The consideration of technological spillover is plausible, given that there are suppliers' associations in the Japanese automobile industry (see Sako [1996], Aoki and Lennerfors [2013]). In addition, some major parts suppliers have joined multiple suppliers' associations (Sako [1996, p. 656]), which fosters mutual learning among parts suppliers (Sako [1996, p. 664]).

As summarized in Matsushima and Mizuno [2013, Section 5.1], Japanese suppliers have stronger bargaining power over automobile assemblers than their U.S. counterparts. Furthermore, the degrees of vertical integration 
in those manufacturers are smaller than those in their U.S. counterparts (Cusumano and Takeishi [1991]).

In sum, our paper provides another plausible explanation for the difference between the organizational structures of Japanese and U.S. automobile assemblers. The differences of the two countries between the degrees of R\&D spillovers and between the upstream sectors' bargaining power are the key reasons for the difference between the organizational structures of Japanese and U.S. automobile assemblers.

\section{V(iv). Discussion}

In Sections V(i)-V(iii), we consider spillovers on investment to investigate market environments in which vertical separation can occur. We briefly discuss a duopoly competition without spillovers on investment to explain that spillovers on investment in themselves are not essential for vertical separation to occur.

Let us consider the inverse demand in (8) and the following marginal cost and investment cost functions of firm $i$ :

$$
c_{i}=1-\left(e_{i}+e_{j}\right)^{1 / 5} \text { and } I^{i}\left(e_{i}, e_{j}\right)=2 e_{i}^{2} .
$$

In this scenario, there is no spillover on investment (as in Cases 2 and 3 in Table II, $\delta=0$ ). Furthermore, the efforts of the firms have a public good nature (as in Section $\mathrm{V}(\mathrm{i}), \theta=1$ ) in the sense that $e_{i}$ reduces the marginal cost of firm $j$ as much as that of firm $i$. However, the marginal cost is not linear in $e_{i}$ and $e_{j}$. Amir et al. [2003] use a similar functional form to discuss a general form of R\&D spillovers on production in a standard duopoly model.

For functional forms of the type $\left(e_{1}+e_{2}\right)^{\alpha}$ with $\alpha<1$, the marginal cost is concave with respect to $e_{i}$. The concavity substantially influences the incentives of the firms to reduce their marginal costs. When the value of $\alpha$ is small enough (the concavity of $\left(e_{1}+e_{2}\right)^{\alpha}$ is significant), as is the case for $\alpha=1 / 5$, only one of the firms' efforts is sufficient to achieve a reasonable level of cost reduction. This implies that the iso-profit curve is convex with respect to its investment level. In addition, the reaction curve is downward sloping, in such a way that this scenario belongs to Case $1 .{ }^{16}$ As a consequence, following Theorem 1 and along with Proposition 1, firms adopt vertical separation if the upstream sectors' bargaining power is large enough.

Result 2. When the market is defined by Equations 8 and 15,

1. if $\beta^{1}>\widehat{\beta}_{S}^{1}\left(\beta^{2}\right)$ and $\beta^{2}>\widehat{\beta}_{S}^{2}\left(\beta^{1}\right)$, where $\hat{\beta}_{S}^{i}\left(\beta^{j}\right)$ is in Figure 3 , the firms vertically separate (area $B$ in Figure 3 );

16 Recall that in Section V(i), with linear production costs, full spillovers on production $(\theta=1)$, and no spillovers on investment $(\delta=0)$, the reference case is Case 2 . Then, the only equilibrium is where both firms vertically integrate. 


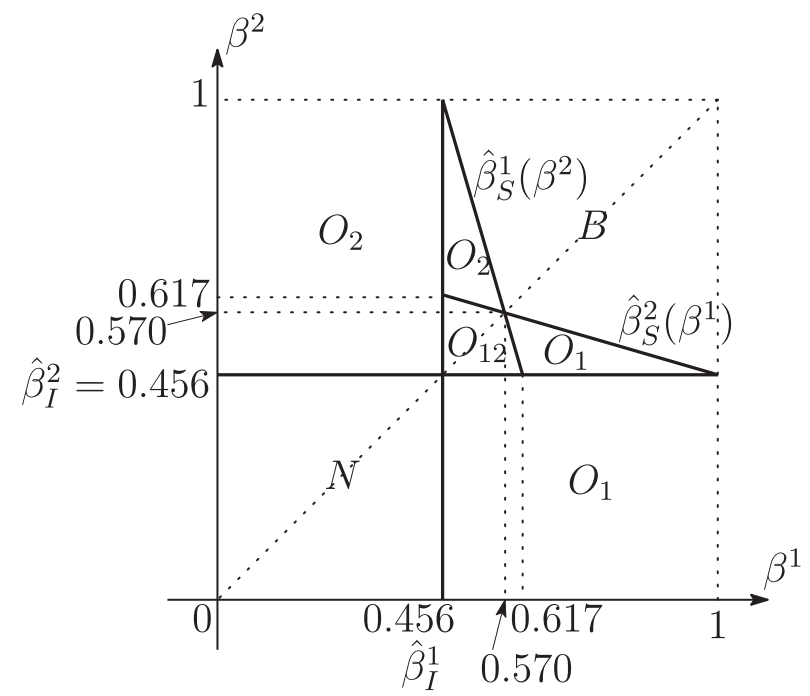

Figure 3

Equilibrium Vertical Structures under Case $1(\alpha=1 / 5, \theta=1)$

Notes: $B$ : Both separate; $O_{1}$ : Only firm 1 separates; $O_{2}$ : Only firm 2 separates; $O_{12}$ : Only one of the firms separates; $N$ : No firm separates. (The threshold curves $\widehat{\beta}_{S}^{i}\left(\beta^{j}\right)$ are not straight lines).

2. if $\beta^{i}>0.456$ and $\beta^{j} \leq 0.456$ or if $\beta^{i}>\widehat{\beta}_{S}^{i}\left(\beta^{j}\right)$ and $0.456<\beta^{j} \leq \widehat{\beta}_{S}^{j}\left(\beta^{i}\right)$, then firm $i$ vertically separates and firm $j$ vertically integrates (area $O_{i}$ $(i=1,2)$ in Figure 3);

3. if $0.456<\beta^{i} \leq \widehat{\beta}_{S}^{i}\left(\beta^{j}\right)$ for $i, j=1,2(j \neq i)$, there are two possible equilibria in which one of the two firms separates and the other integrates (area $O_{12}$ in Figure 3);

4. otherwise, in equilibrium, no firm separates (area $N$ in Figure 3).

This illustrates the importance of the functional form of the market and the robustness of the conclusions obtained with linear functional forms. ${ }^{17}$

The relation between the equilibrium organizational structures and the parameters of bargaining power, $\beta^{1}$ and $\beta^{2}$, is similar to that in Proposition 1 except for the existence of asymmetric equilibria (area $O_{12}$ ) in Result 2.

The conclusions in Results 1 and 2 differ because of the difference in how investment efforts reduce the marginal cost under the two cost structures. In both structures, if a firm's opponent vertically separates, adopting vertical separation has three direct effects on the firm: (i) underinvestment from the viewpoint of the vertical chain; (ii) a lower reduction in production cost; and (iii) a reduction of its R\&D cost. The first effect is similar in

17 The Mathematica file to derive Figure 3 is available upon request. 
the two cost structures. The second effect is milder in the first cost structure because of the linearity of the marginal cost. The third effect, the only positive one, is larger in the first cost structure because of the direct spillover on investment. In addition to these three direct effects, the adoption of vertical separation has an indirect impact on the rival's R\&D effort. In essence, the indirect impact enhances the rival's effort, which recovers the loss from the second direct effect and enlarges the spillover on investment in the first cost structure. This positive indirect effect is larger in the first cost structure because of the linearity of $c_{i}$. However, the spillover on investment partially offsets the gain from this positive effect. In total, adopting vertical separation is less costly in the first cost structure in Section V(iii), in which the marginal cost is linear in efforts. As a result, in the first cost structure, there is the area $B N$ in which a firm follows its opponent's adoption of vertical separation, and multiple symmetric equilibria can emerge.

\section{CONCLUSION}

In oligopolistic industries, understanding why firms adopt vertical integration or separation has attracted a great deal of attention. However, we are still far from understanding the whole picture, and there is no apparent and straightforward reason for firms' decisions to integrate or not. Various authors explain the gains that firms will derive from meeting their input requirements internally or externally (see Section II). In addition to the market structure, some studies include process R\&D among the determinants, although very few consider the possible R\&D spillovers in the analysis. To our knowledge, no studies investigate the effects of positive or negative spillovers on the rival's R\&D investment. Our paper is thus a first step toward clarifying the importance of the technological environment when we consider the equilibrium organizational structures of firms in oligopolistic markets.

We stress the interaction between incentives for R\&D, R\&D spillovers, and firms' decisions regarding their organizational structures. In this paper, we consider a general and flexible framework for market competition environments, which includes R\&D spillovers on production and on investment. This framework allows us to present the conditions that determine the firms' organization decisions, and to understand how the combination of the characteristics of the final good market and those of the R\&D process (incentives and spillovers) makes the strategy of integration superior or inferior to the strategy of adopting vertical separation.

In our model, the forces at work come from the market conditions (as a function of the demand and the market competition), how a firm's R\&D decisions influence its production cost, and how the rival's R\&D efforts affect the firm through spillovers on production and those on investment. Those factors interact with the fact that the incentives to perform R\&D in a vertical chain are greater under vertical integration. 
We show that the equilibrium organizational structure depends on whether the situation belongs to one of four cases. They depend on whether R\&D investments are mutually beneficial or not, and whether investment efforts are strategic substitutes or complements. When R\&D investments are mutually helpful, and investment efforts are strategic substitutes, or when R\&D investments are not mutually beneficial, and investment efforts are strategic complements, vertical separation can emerge. In the remaining two cases, however, vertical separation never occurs in equilibrium. In the former two cases, the degrees of upstream sectors' bargaining power in the two vertical chains are critical for a vertical separation to emerge or not. If the degree of an upstream sector's bargaining power is sufficiently high, the vertical chain decides to separate vertically. Conversely, if the degree of an upstream sector's bargaining power in a vertical chain is not high, this vertical chain is more likely to integrate vertically. Interestingly, even in entirely symmetric environments, it can be the case that two vertical chains adopt different organizational structures in equilibrium.

The effects analyzed in our paper may help us to understand other contexts. Instead of considering firms competing in the production market and making decisions regarding $\mathrm{R} \& \mathrm{D}$ efforts, one can consider, for instance, advertising expenditures that could have (positive or negative) effects on the rival's demand or sales and its cost of advertising. There, vertical separation could be a way to commit to underinvest in advertising.

Our analysis clarifies that we cannot reach conclusions on which vertical integration strategy is better without considering both technological and competitive perspectives together. For example, as we have illustrated in Section V, we cannot conclude that the level of integration depends negatively on the degree of spillovers in the industry: the technological environment in the industry matters. Therefore, we need to be cautious regarding the importance of knowledge and R\&D spillovers that previous studies on vertical organizations have not considered. This caveat can be useful for empirical studies on firms' behavior because bypassing the $\mathrm{R} \& \mathrm{D}$ decisions and its spillovers may induce researchers to assign to market competition the realized vertical structure for which R\&D investments are accountable.

In this paper, we have omitted several important issues that also determine the firms' optimal organization decisions. Further research will resolve these difficult questions about why some firms decide to integrate their sectors, and others to separate them.

\section{APPENDIX}

Proof of Theorem 1. In Case 1, irrespective of firm 2's vertical structure, vertical separation in firm 1 causes a leftward shift of firm 1's reaction function, inducing a left-upward shift of the Nash equilibrium because of the downward sloping of firm 
2's reaction function. ${ }^{18}$ Because the slope of firm 1's iso-profit curve is zero and the slope of firm 2's best response curve is negative at the original Nash equilibrium, there is an $\epsilon>0$ such that $\left(e_{1}^{*}-\epsilon, \bar{e}_{2}\right)$ is on firm 1's iso-profit curve passing through the original Nash equilibrium $\left(e_{1}^{*}, e_{2}^{*}\right)$ and $\bar{e}_{2}<e_{2}^{k}\left(e_{1}^{*}-\epsilon\right)$, where $k \in\{I, S\}$ represents the organizational structure of firm 2, Integration or Separation. We obtain $\Pi^{1}\left(e_{1}^{*}, e_{2}^{*}\right)=\Pi^{1}\left(e_{1}^{*}-\epsilon, \bar{e}_{2}\right)<\Pi^{1}\left(e_{1}^{*}-\epsilon, e_{2}^{k}\left(e_{1}^{*}-\epsilon\right)\right)$ because $\Pi_{2}^{1}>0$. Because firm 1's best response $e_{1}^{S}\left(e_{2}\right)$ is continuous and increasing in $\beta^{1}$ for any $e_{2}$ (see (4)), the above inequalities imply that there exists $\widehat{\beta}_{k}^{1}<1$, such that firm 1 prefers vertical separation to integration for any $\beta^{1} \in\left[\widehat{\beta}_{k}^{1}, 1\right)$.

In Case 2, irrespective of firm 2's vertical structure, vertical separation in firm 1 causes a leftward shift of firm 1's reaction function, inducing a left-downward shift of the Nash equilibrium because of the upward sloping of firm 2's reaction function. We check the effect of the left-downward shift of the Nash equilibrium on firm 1 in two steps. A leftward shift of the equilibrium point from the original Nash equilibrium decreases the profit of firm 1. Moreover, a downward shift of $e_{2}$ further decreases the profit of firm $1\left(\Pi_{2}^{1}>0\right)$. Therefore, a left-downward shift of the Nash equilibrium through vertical separation harms firm 1 . We can apply the same logic to the effect of vertical separation on firm 2.

In Case 3, irrespective of firm 2's vertical structure, vertical separation in firm 1 causes a leftward shift of firm 1's reaction function, inducing a left-upward shift of the Nash equilibrium because of the downward sloping of firm 2's reaction function. We check the effect of the left-upward shift of the Nash equilibrium on firm 1 in two steps. A leftward shift of the equilibrium point from the original Nash equilibrium decreases the profit of firm 1. Moreover, an upward shift of $e_{2}$ also decreases the profit of firm $1\left(\Pi_{2}^{1}<0\right)$. Therefore, a left-upward shift of the Nash equilibrium through vertical separation harms firm 1 . We can apply the same logic to the effect of vertical separation on firm 2.

In Case 4, irrespective of firm 2's vertical structure, vertical separation in firm 1 causes a leftward shift of firm 1's reaction function, inducing a left-downward shift of the Nash equilibrium because of the upward sloping of firm 2's reaction function. Because the slope of firm 1's iso-profit curve is zero and the slope of firm 2's best response is positive at the original Nash equilibrium, then there is an $\epsilon>0$, such that $\left(e_{1}^{*}-\epsilon, \bar{e}_{2}\right)$ is on firm 1's iso-profit curve passing through the original Nash equilibrium $\left(e_{1}^{*}, e_{2}^{*}\right)$ and $\bar{e}_{2}>e_{2}^{k}\left(e_{1}^{*}-\epsilon\right)$, where $k \in\{I, S\}$ represents the organizational structure of firm 2. We obtain $\Pi^{1}\left(e_{1}^{*}, e_{2}^{*}\right)=\Pi^{1}\left(e_{1}^{*}-\epsilon, \bar{e}_{2}\right)<\Pi^{1}\left(e_{1}^{*}-\epsilon, e_{2}^{k}\left(e_{1}^{*}-\epsilon\right)\right)$ because $\Pi_{2}^{1}<0$. Because firm 1's best response $e_{1}^{S}\left(e_{2}\right)$ is continuous and increasing in $\beta^{1}$ for any $e_{2}$ (see (4)), the above inequalities imply that there exists $\tilde{\beta}_{k}^{1}<1$, such that firm 1 prefers vertical separation to integration for any $\beta^{1} \in\left[\tilde{\beta}_{k}^{1}, 1\right)$.

Q.E.D.

18 The shift of the Nash equilibrium referred to in this proof is guaranteed by the condition

$$
\left|\frac{d e_{2}^{k}\left(e_{1}\right)}{d e_{1}}\right|<\left|\frac{1}{d e_{1}^{I}\left(e_{2}\right) / d e_{2}}\right| \quad(k=I, S),
$$

which implies that irrespective of firm 2's organizational structure, the slope of firm 1's best response is steeper than that of firm 2's best response. This condition seems innocuous because it guarantees the stability of the Nash equilibrium. The numerical examples presented later satisfy this condition. 


\section{REFERENCES}

Ahmadjian, C. L. and Lincoln, J. R., 2001, 'Keiretsu, Governance, and Learning: Case Studies in Change from the Japanese Automotive Industry,' Organization Science, 12, pp. 683-701.

Amir, R.; Evstigneev, I. and Wooders, J., 2003, 'Noncooperative versus Cooperative R\&D with Endogenous Spillover Rates,' Games and Economic Behavior, 42, pp. 183-207.

Aoki, K. and Lennerfors, T. T., 2013, 'Whither Japanese keiretsu? The Transformation of Vertical keiretsu in Toyota, Nissan and Honda 1991-2011,' Asia Pacific Business Review, 19, pp. 70-84.

Armour, H. O. and Teece, D. J., 1980, 'Vertical Integration and Technological Innovation,' Review of Economics and Statistics, 62, pp. 470-474.

Bernstein, J. I. and Nadiri, M. I., 1989, 'Research and Development and Intra-Industry Spillovers: An Empirical Application of Dynamic Duality,' Review of Economic Studies, 56, pp. 249-267.

Bolton, P. and Whinston, M. D., 1993, 'Incomplete Contracts, Vertical Integration, and Supply Assurance,' Review of Economic Studies, 60, pp. 121-148.

Bonanno, G. and Vickers, J., 1988, 'Vertical Separation,' Journal of Industrial Economics, 36, pp. 257-265.

Bresnahan, T. F. and Levin, J. D., 2013, 'Vertical Integration and Market Structure,' in Gibbons, R., and Roberts, J. (eds.) Handbook of Organizational Economics (Princeton University Press, Princeton, New Jersey, U.S.A.), pp. 853-890.

Buehler, S. and Schmutzler, A., 2008, 'Intimidating Competitors - Endogenous Vertical Integration and Downstream Investment in Successive Oligopoly', International Journal of Industrial Organization, 26, pp. 247-265.

Caillaud, B. and Rey, P., 1995, 'Strategic Aspects of Vertical Delegation,' European Economic Review, 39, pp. 421-431.

Chen, Y., 2001, 'On Vertical Mergers and their Competitive Effects,' RAND Journal of Economics, 32, pp. 667-685.

Chen, Y., 2005, 'Vertical Disintegration,' Journal of Economics \& Management Strategy, 14, pp. 209-229.

Chen, Y. and Sappington, D. E. M., 2010, 'Innovation in Vertically Related Markets,' Journal of Industrial Economics, 58, pp. 373-401.

Choi, J. P. and Yi, S.-S., 2000, 'Vertical Foreclosure with the Choice of Input Specifications,' RAND Journal of Economics, 31, pp. 717-743.

Cohen, W. M.; Goto, A.; Nagata, A.; Nelson, R. R. and Walsh, J. P., 2002, 'R\&D Spillovers, Patents and the Incentives to Innovate in Japan and the United States,' Research Policy, 31, pp. 1349-1367.

Cohen, W. M. and Levinthal, D. A., 1989, 'Innovation and Learning: The Two Faces of R\&D,' Economic Journal, 99, pp. 569-596.

Crépon, B. and Duguet, E., 1997, 'Research and Development, Competition and Innovation Pseudo-Maximum Likelihood and Simulated Maximum Likelihood Methods Applied to Count Data Models with Heterogeneity,' Journal of Econometrics, 79, pp. 355-378.

Cusumano, M. and Takeishi, A., 1991, 'Supplier Relations and Management: A Survey of Japanese, Japanese-Transplant, and U.S. Auto Plants,' Strategic Management Journal, 12, pp. 563-588.

d'Aspremont, C. and Jacquemin, A., 1988, 'Cooperative and Noncooperative R\&D in Duopoly with Spillovers,' American Economic Review, 78, pp. 1133-1137.

Dixit, A., 1979, 'A Model of Duopoly Suggesting a Theory of Entry Barriers,' Bell Journal of Economics, 10, pp. 20-32. 
Dyer, J., 1996, 'Does Governance Matter? Keiretsu Alliances and Asset Specificity as Sources of Japanese Competitive Advantage,' Organization Science, 7, pp. 649-666.

Emerson, R. M., 1962, 'Power-Dependence Relations,' American Sociological Review, 27, pp. 31-40.

Fudenberg, D. and Tirole, J., 1984, 'The Fat-Cat Effect, the Puppy-Dog Ploy, and the Lean and Hungry Look,' American Economic Review, 74, pp. 361-366.

Gal-Or, E., 1999, 'Vertical Integration or Separation of the Sales Function as Implied by Competitive Forces,' International Journal of Industrial Organization, 17, pp. 641-662.

Gibbons, R., 2005, 'Four Formal(izable) Theories of the Firm?', Journal of Economic Behavior and Organization, 58, pp. 200-245.

Grossman, S. and Hart, O., 1986, 'The Costs and Benefits of Ownership: A Theory of Vertical and Lateral Integration,' Journal of Political Economy, 94, pp. 691-719.

Gupta, S., 2008, 'Channel Structure with Knowledge Spillovers,' Marketing Science, 27, pp. 247-261.

Gupta, S. and Loulou, R., 1998, 'Process Innovation, Product Differentiation, and Channel Structure: Strategic Incentives in a Duopoly,' Marketing Science, 17, pp. 301-316.

Hart, O., 1995, Firms, Contracts, and Financial Structure (Oxford University Press, Oxford, England).

Hart, O. and Moore, J., 1990, 'Property Rights and the Nature of the Firm,' Journal of Political Economy, 98, pp. 1119-1158.

Hart, O. and Tirole, J., 1990, 'Vertical Integration and Market Foreclosure', Brookings Papers on Economic Activity Microeconomics, 21, pp. 205-276.

Hill, C. W. L., 1995, 'National Institutional Structures, Transaction Cost Economizing, and Competitive Advantage: The Case of Japan,' Organization Science, 6, pp. 119-131.

Klein, B.; Crawford, R. and Alchian, A., 1978, 'Vertical Integration, Appropriable Rents, and the Competitive Contracting Process,' Journal of Law and Economics, 21, pp. 297-326.

Legros, P. and Newman, A. F., 2013, 'A Price Theory of Vertical and Lateral Integration,' Quarterly Journal of Economics, 128, pp. 725-770.

Legros, P. and Newman, A. F., 2014, 'Contracts, Ownership, and Industrial Organization: Past and Future,' Journal of Law, Economics, and Organization, 30, pp. i82-i117.

Lin, P., 2006, 'Strategic Spin-Offs of Input Divisions,' European Economic Review, 50, pp. 977-993.

Lin, Y.-T.; Parlaktürk, A. K. and Swaminathan, J. M., 2014, 'Vertical Integration under Competition: Forward, Backward, or No Integration?', Production and Operations Management, 23, pp. 19-35.

Liu, X., 2016, 'Vertical Integration and Innovation,' International Journal of Industrial Organization, 47, pp. 88-120.

Loury, G. C., 1979, 'Market Structure and Innovation,' Quarterly Journal of Economics, 93, pp. 395-410.

Matsushima, N., 2009, 'Vertical Merger and Product Differentiation,' Journal of Industrial Economics, 57, pp. 812-834.

Matsushima, N. and Mizuno, T., 2013, 'Vertical Separation as a Defense against Strong Suppliers,' European Journal of Operational Research, 228, pp. 208-216.

Milliou, C., 2008, 'Technological Proximity and Exclusive Buyer-Supplier Relationships,' B.E. Journal of Economic Analysis \& Policy, 8, Iss. 1 (Advances), article 25.

Milliou, C. and Petrakis, E., 2012, 'Vertical Integration, Knowledge Disclosure and Decreasing Rival's Cost,' working paper 12-13 (Universidad Carlos III de Madrid, Department of Economics, Madrid, Spain).

Milliou, C. and Petrakis, E., 2019, 'Vertical Integration and Knowledge Disclosure,' Economics Letters, 177, pp. 9-13. 
Perry, M. K., 1989, 'Vertical Integration,' in Schmalensee, R., and Willing, R. (eds.) Handbook of Industrial Organization. Vol. 1, pp. 1985-2055 (North-Holland Press, Amsterdam, the Netherlands).

Pfeffer, J. and Salancik, G., 1978, The External Control of Organizations (Harper \& Row, New York, New York, U.S.A.).

Rey, P. and Tirole, J., 2007, 'A Primer on Foreclosure,' in Armstrong, M., and Porter, R. (eds.) Handbook of Industrial Organization. Vol. 3. (Elsevier Publishers, Amsterdam, the Netherlands), pp. 2145-2220.

Rockett, K., 1990, 'The Quality of Licensed Technology,' International Journal of Industrial Organization, 8, pp. 559-574.

Sako, M., 1991, 'The Role of 'Trust' in Japanese Buyer-Supplier Relationships,' Richerche Economiche, 45, pp. 449-474.

Sako, M., 1996, 'Suppliers' Association in the Japanese Automobile Industry: Collective Action for Technology Diffusion,' Cambridge Journal of Economics, 20, pp. 657-671.

Scherer, F. M., 1980, Industrial Market Structure and Economic Performance, 2nd edition (Rand-McNally, Chicago, Illinois, U.S.A.).

Singh, N. and Vives, X., 1984, 'Price and Quantity Competition in a Differentiated Duopoly,' RAND Journal of Economics, 15, pp. 546-554.

Spence, M., 1984, 'Cost Reduction, Competition, and Industry Performance,' Econometrica, 52, pp. 101-122.

Wang, S.; Hu, Q. and Liu, W., 2017, 'Price and Quality-Based Competition and Channel Structure with Consumer Loyalty,' European Journal of Operational Research, 262, pp. $563-574$.

Williamson, O. E., 1975, Markets and Hierarchies: Analysis and Antitrust Implications. (Free Press, New York, New York, U.S.A.).

Ziss, S., 1995, 'Vertical Separation and Horizontal Mergers,' Journal of Industrial Economics, 43, pp. 63-75. 